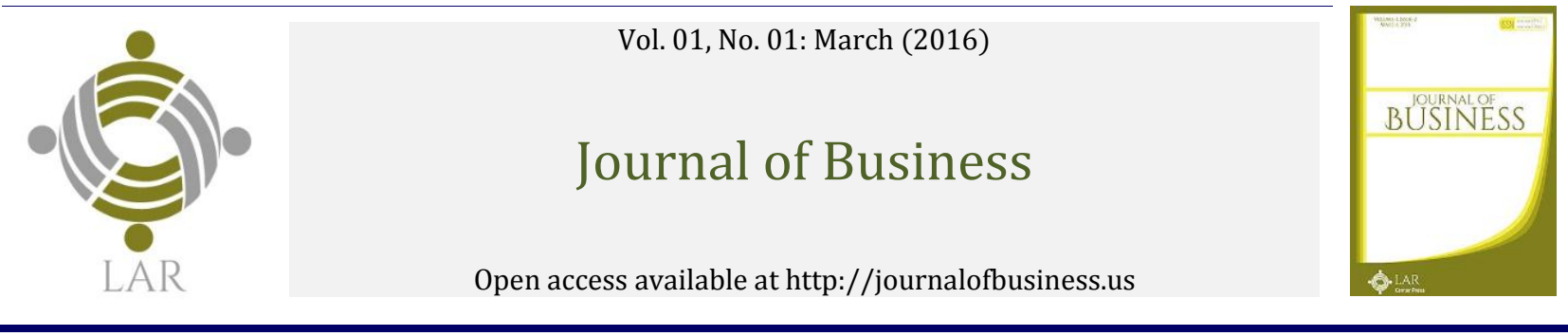

\title{
Portfolio Management and Appropriation of Private Benefits of Control
}

Elli Kraizberg a*,

a School of Business, Bar Ilan University, Ramat Gan 52900, Israel.

${ }^{*}$ Corresponding author's email address: ekraizberg@yahoo.com.

\section{A R T I C L E I N F O}

Received: 25-01-2016

Accepted: 21-02-2016

Available online: $05-03-2016$

Keywords:

Benefits of Control, portfolio management, Efficient transfer.

JEL Classification: G32, K4

\section{A B S T R A C T}

In many countries around the globe, portfolio managers utilize well-accepted models, assuming that a partial stake of ownership is proportionally valued. This assumption is incorrect in markets in which traded firms or publicly held firms are controlled by major owners who would take any possible measure to protect and maintain a 'lock' on control, so they can secure a sellable asset to another control seeker. In this case, estimation of key parameters such as, volatility, expected returns and diversification effect, may be grossly distorted. We would argue that a major trigger for the value of the benefits of control is the ability of control owners to transfer assets from their own portfolio to a controlled publicly traded firm. While it is obvious that these transfers will take place, if and only if, it is beneficial to the control owners, the impact on the minor shareholders may not necessarily be negative and may vary depending on several parameters. This paper models a specific drive on the part of control seekers who, in addition to their stake in a publicly traded firm, own a private portfolio. It could be argued that they may 'transfer' inferior investments to the public firms that they control exploiting less than perfect transparency. However, while they own this valuable option of 'transferring' inferior investments into the public firm, these actions may still be beneficial to the minority shareholders. A simulation procedure that are applied to several cases in which transfers are made in exchange for cash or equity, instances of full disclosure or partial transparency, the likelihood that the control owners' actions will be contested in court, level of risk, and other parameters.

This is an open access article under the terms of the Creative Commons Attribution License 4.0, which allows use, distribution and reproduction in any medium, provided the original work is properly cited.

DOI: http://dx.doi.org/10.18533/job.v1i1.17

ISSN: 2380-4041 (Print), 2380-405X (Online)

\subsection{The key issues}

In many countries publicly traded firms are controlled by major shareholders who will typically instigate any and all measures to protect and maintain a 'lock' on control, so they can secure a sellable asset to other control seekers. In countries where a structure composed of majority owned shares is commonplace, temptation must be induced to extract control benefits. By contrast, in places where the extraction of control benefits is overlooked or tolerated, it will lead to a controlling ownership structure.

However, disregarding the private benefits of control may lead to a significant distortion of the analytical valuation of the price of a tradable single share that may lead to inefficient capital markets. In addition to the practical issue of valuation, researchers have also singled out the moral issues related to the redistribution of wealth. The consensus in the literature is that the extraction of private benefits by control owners is an undesirable ill-rooted phenomenon that calls for all kinds of monitoring mechanisms to curb the ability of control owners to extract these benefits. Admati, Pfleiderer and Zechner (1994) analyzed equilibrium, despite the fact that minority shareholders have little incentive to monitor the performance of any of these companies. 
Shleifer and Vishny (1997) argued that increased market competition can limit private benefits by reducing the rents available to be diverted. Bebchuk (1994) examined the Equal Opportunity Rule as a measure to curb inefficient transfers among control seekers. Zingales (2000) claimed that reputation is a powerful source of discipline and a potential loss of reputation may be a powerful deterrent. Roe (1990), La Porta, Lopez-deSalines, Shleifer (2000) and Coffee (2001), among many others more recently, have discussed the role of institutional factors and the idea of an internal policeman of moral norms. They tend to believe that a legal approach is a more fruitful way to understand corporate governance.

The second issue raised in the literature stems from interest in identifying the drives behind control seekers. Basically, why would someone be willing to pay such a high price above the value of the dividend claim, simply for the privilege of obtaining controlling 'power'? It is clear from the data on transactions between control seekers that they are willing to pay a price that exceeds, on per-share basis, the value of the dividend claim. But it is much less clear-cut to identify the sources of the benefits of control that make this type of 'power' so valuable. Harris and Raviv (1988) and to some extent Milnor and Shapely (1978) all argued that the drive for 'power' is the key factor in determining the benefits of control. Demsetz and Lehn (1985) ${ }^{1}$ borrowed Jensen and Mckling's (1977) notion of managerial incentives to extract non-pecuniary perks and applied it to the "shirking owners" who appropriate the firm's resources for their own private benefits where "these benefits accrue entirely to them". Dyck and Zingales (2004) mentioned the transfer of assets, which can be overpriced in relation to the fair price, as the main benefit of control. They pointed out that "educated economists can legitimately disagree on what constitutes the 'fair' transfer price of a certain asset or product" so that if the case is litigated, a court would be reluctant to intervene.

The final issue raised in the literature involves measurement. If there is concrete measurable evidence of appropriation of resources from the rightful owner, the firm, by the control owners, we would not even need court intervention to reclaim it, since the market price would reflect the so-called 'theft'. A lack of transparency is clearly in the interest of the control owners and they will do everything possible to conceal these types of actions. Thus, the private benefits of control are difficult to trace.

Two data sources have been used to estimate the magnitude of the benefits of control. Their implementation implies that the value of control imbedded in transaction data reflects the size of these benefits. Barclay and Holderness (1989) inferred the value of control from the difference between the block trading price between control seekers and the price of similar shares traded on the stock exchange. The difficulty with this method is the assumption that publicly traded prices do not reflect the value of control, since some of this value of control is reflected in the publicly traded price, as a speculative premium in lieu of a potential proxy fight. Dyck and Zingales (2004) estimated the value of control inferred from block trading using data from 39 countries, and identified 29 relevant variables. A second type of data was used by Bergstrom and Rydqvist (1990), Nenova (2001) and others, who estimated the market value of voting rights from the differences in prices of dual-class shares. These shares have voting rights which are not proportional to the dividend claims. Once again, the inferred value reflects transactions on a public exchange, whereas control seekers, who transfer blocks of shares, generally trade out of the public exchange.

\subsection{The framework of this paper}

This paper differs in several ways from the literature presented above. First, we believe that the moral issue should be phrased differently. In a world of perfect symmetric information and full transparency, the benefits of control would be fully imbedded in market prices, and would make it possible to separate market share from controlling share. Consider a hypothetical world where minority shareholders have perfect knowledge of the private benefits extracted by the control owners and in addition, assume that inefficient transfers between control seekers that negatively affect minority shareholders would conform to the Pareto rule, along the lines presented by Bebchuk In this case two assets would be traded independently: one that reflects a claim for dividends and the other the value of control benefits. In other words, minority shareholders would purchase shares whose values were short of the value of control. Thus, this moral hazard issue is directly related to the level of transparency. This paper argues that reducing the level of transparency is a major interest of the control owners, as will be shown below. The 'depth' of the issue is related to the extent of disclosure requirements and enforcement in a given country's corporate world. It is more than likely that a lack of transparency is the result of a system of powerful control owners with vested interests and not the cause. Thus, a variety of monitoring governances should be enforced to achieve full disclosure and transparency and deal less with outright prohibitions. Our framework will imbed the level of transparency.

\footnotetext{
${ }^{1}$ Also Fluck (1999) and others.
} 
Second, and more importantly, the benefits of control are not entirely "private"; i.e., they are not entirely devolved to the appropriation and diversion of the resources of publicly traded firms for the benefit of the control owners. In some realistic circumstances, control benefits can be shared by the minority shareholders. Expanding on a comment similar to the remark by Dyck and Zingales, it can be claimed that a major trigger for the value of the benefits of control is the ability of control owners to transfer assets from their own portfolio to a controlled publicly traded firm. While clearly these transfers only take place if they are beneficial to the control owners, the impact on the minority shareholders may not necessarily be negative and may vary depending on several parameters.

Third, there is no analytical framework in the literature that evaluates the private benefits of control and given the consensus in the literature, as stated above, that publicly available empirical data does not accurately reflect the private benefits of control, a need for a formal analytical framework becomes apparent.

Given the above assertions, this paper establishes an innovative analytical framework that models a specific drive on the part of control seekers who, in addition to their stake in a publicly traded firm, own a private portfolio. It could be argued that they may 'transfer' inferior investments to the public firms that they control exploiting less than perfect transparency. However, while they own this valuable option of 'transferring' inferior investments into the public firm, these actions may still be beneficial to the minority shareholders. Control owners are assumed to have a variety of investments in their portfolio. This includes a significant stake in the publicly traded firm with the remaining investments in closely held by private companies. Eventually, they may go public with their private portfolio and subsequently start creating a new private portfolio. They face a spectrum of investments opportunities which are not accessible to the minority shareholders of public firms, so they may possess superior information or greater accessibility to new investment opportunities. The outcomes of these investment opportunities are uncertain, but after making a new investment, a partial resolution of uncertainty takes place. There is a high probability they will be able to transfer these investments to the public firm. They rank these investments in terms of several criteria such as expected return, risk, marginal diversification effect on their overall exposure to risk, collaterability of these investments for funding purposes, synergy, etc. The least desirable investments, from their point of view, are the candidates for transfers to their public firm in exchange for equity or cash that will be used for new investments.

Although the statement risks a libel suit, it could be claimed that the benefits of control stem from the ability of control owners to use public companies as the 'trash can' for their investments elsewhere. Obviously this is extreme as long as transfers of assets take place at a 'fair' price so that the minority shareholders are not harmed. Likewise, the argument that the superior information that may be possessed by the control owners' accessibility to investment opportunities, is their "own property"; hence the public company has no proprietary rights. The transfers that take place above the 'fair' price may still be beneficial to the minority shareholders under certain circumstances.

Whether or not control owners have proprietary rights to the benefits of superior information is well beyond the scope of this paper, but it leads to the next point. The so-called private benefits of control are usually defined as benefits that are extracted by control owners and are not shared by other shareholders. This type of definition implies that a portion of the value of the firm is redistributed unequally among shareholders. However some of the benefits of control that can be extracted by control owners are not necessarily a portion of the value of equity of the firm and the issue of who is the rightful owner is a normative one and should be dealt with by law scholars.

This framework, short of normative statements, will be modeled in the next section. Control owners in a publicly traded firm have two types of claims. The first is a claim for dividends that are traded continuously with a given risk-adjusted expected return. The second is a claim that potentially can be traded among control seekers with a higher risk-adjusted expected return. The model below values the difference between the rates of return, in a setting in which control owners derive their benefits of control from the strategies described above.

The remainder of this paper is structured in three steps. First, the idea is presented in a simple one-period discrete framework. Then the framework is generalized to a case of lack of full transparency, unrestricted game, where payments are either made by cash or by equity. Then, a framework restriction on the payoff to be Pareto optimal is imposed so that minority shareholders are not worse off. Finally, the analytical solutions will be simulated under various parameters that can be estimated empirically with an acceptable level of accuracy. The simulation procedure are applied to several cases in which transfers are made in exchange for cash or equity, instances of full disclosure or partial transparency, the likelihood that the control owners' actions will be contested in court, level of risk, and other parameters. The model findings can then be compared with empirical 
data. We expect that the empirical findings will demonstrate higher benefits of control that stem from other sources that are not part of the model.

\subsection{The basic framework}

Assume that well-endowed control owners face uncertain opportunity sets of investments. Their portfolio has an overall value of $\overline{\boldsymbol{V}}$ and it contains several holdings:

The first is $\boldsymbol{\alpha}_{\mathbf{1}}$ of their holdings in closely held private investments with a risk adjusted expected rate of return of $\boldsymbol{r}_{\boldsymbol{p}}$. Some uncertainty about these held investments has been resolved and the distributional characteristics of the returns are known.

The second is $\boldsymbol{\alpha}_{2}$ of their holdings in the $\beta$ of the shares of a publicly traded firm whose assets bear the risk adjusted expected rate of return of $\boldsymbol{r}_{\boldsymbol{b}}$, which might as well be the riskless rate of return.

The third is $\boldsymbol{\alpha}_{3}, \boldsymbol{\alpha}_{3}=\mathbf{1}-\boldsymbol{\alpha}_{\mathbf{1}}-\boldsymbol{\alpha}_{2}$ of their holdings in a new investment that has just been undertaken, or a new investment is being contemplated given an asking price of $\boldsymbol{X}=\boldsymbol{\alpha}_{3} \overline{\boldsymbol{V}}$. Initially there is uncertainty about the expected rate of return, $\boldsymbol{r}_{\boldsymbol{n}}$ but immediately after the purchase, some uncertainty is resolved.

It is assumed that $\boldsymbol{r}_{\boldsymbol{p}} \geq \boldsymbol{r}_{\boldsymbol{b}}$. This assumption is critical for the claim that not all control benefits are 'private', but in a world of asymmetric information and lack of transparency, this assumption is not critical for the overall thesis regarding the trigger for the benefits of control. The assumption also implies that the control owners can gain by going public with their private portfolio.

The control owners may contemplate transferring the new investment into the public firm in exchange for cash or equity in addition to the $\boldsymbol{\beta}$ of the shares that they already own. The likelihood that this transfer will be approved is $\gamma$ which could be represented by the Milnor and Shapley (1978), or Owen (1972), Teal (1996) power indices.

Initially, the overall expected risk adjusted return is,

$E \bar{r}=\alpha_{1} r_{p}+\alpha_{2} \beta r_{b}+\alpha_{3} E r_{n}+\gamma r_{c}$

Given that his/her holdings in the shares of the public company has a value of,

$\alpha_{2} \bar{V}=\beta\left(V-V_{c}^{\prime}\right)+\gamma V_{c}$

where $\boldsymbol{V}^{\prime}{ }_{\boldsymbol{c}}$ is the value of private benefits of control and $\boldsymbol{r}_{\boldsymbol{c}}$ is the risk adjusted rate of return on the portion of holdings that reflects the benefits of control ${ }^{2}$. If $\boldsymbol{V}^{\prime}{ }_{c}=\boldsymbol{V}_{\boldsymbol{c}}$, the entire benefits of control are private in the sense that all the value of control is attributed to appropriation and diversion of the firm's resources to the control owners. The value of the benefits of control is rationalized in a later section, after the presentation of the following four cases.

Case one is a fair deal, with full transparency and an exchange for cash. Under this definition of a fair deal, the negotiated transfer price, $Y$, is set so that the control owners are indifferent to either retaining the asset or transferring it to their controlled public firm, while the net gains, if any, are allocated to the minority shareholders ${ }^{3}$. If so, the change in the overall rate of return is,

$\Delta \bar{r}=-\alpha_{3} r_{n}+\alpha_{2} \beta f\left(r_{b}, r_{n}\right) \equiv 0$

where $\boldsymbol{f}\left(\boldsymbol{r}_{\boldsymbol{b}}, \boldsymbol{r}_{\boldsymbol{n}}\right)$ is the new rate of return on the firm's assets which depends on the size of the transfer, the size of the private portfolio and the value of the firm. Obviously this action yields no direct benefit to the control owners, while If $\boldsymbol{r}_{\boldsymbol{n}}>\boldsymbol{r}_{\boldsymbol{b}}$, the transfer may be beneficial to the minority shareholders.

The second case is characterized by a lack of transparency, asymmetric information and exchange for cash. The control owners will definitely retain the new investment in their private portfolio if the partially realized expected risk adjusted return is $\boldsymbol{r}_{\boldsymbol{n}} \geq \boldsymbol{r}_{\boldsymbol{p}}$. If, however, $\boldsymbol{r}_{\boldsymbol{n}}<\boldsymbol{r}_{\boldsymbol{p}}$ the control owners can "negotiate" a transfer price with the firm that implies a risk adjusted return of $\boldsymbol{r}_{n}^{\prime}, \boldsymbol{r}_{n}^{\prime}-\boldsymbol{r}_{n}<0$. Note that $\boldsymbol{r}_{\boldsymbol{n}}^{\prime}-\boldsymbol{r}_{n}$ cannot be positive since the control owner may sell it to a third party for a price that implies the true $\boldsymbol{r}_{\boldsymbol{n}}$.

If so, the change in the overall rate of return is,

\footnotetext{
2 If the entire holding was sold to another control seeker.

3 This is obviously not a rational case, since it implies that $\boldsymbol{Y}<\boldsymbol{V}_{\boldsymbol{n}}$ whereas the new investment could be sold elsewhere for $\boldsymbol{V}_{\boldsymbol{n}}$
} 
$\Delta \bar{r}=-\alpha_{3} r_{n}+a_{3}\left(r_{n}^{\prime}-r_{n}\right)+\alpha_{2} \beta f\left(r_{b}, r_{n}-r_{n}^{\prime}\right) \geq 0$

where $\left(\boldsymbol{r}_{\boldsymbol{n}}^{\prime}-\boldsymbol{r}_{\boldsymbol{n}}\right)$, with a negative sign, represents the overpricing effect. However, if $\boldsymbol{r}_{\boldsymbol{n}}^{\prime}>\boldsymbol{r}_{\boldsymbol{b}}$ the overpricing is more than offset by a gain to the firm, so that the overall impact on the equity of the minority shareholders is positive.

The third and the fourth cases depict exchanges for shares. In the event of a fair deal, and given (2),

$\Delta \bar{r}=-\alpha_{3} r_{n}+\alpha_{2} \beta f\left(r_{b}, r_{n}\right)+\Delta \gamma r_{c} \equiv 0$

where $\Delta \boldsymbol{\gamma} \boldsymbol{r}_{\boldsymbol{c}}$ represents the increase in the power held by the control owner if $\Delta \boldsymbol{\gamma}>0$. However, in the case of an unfair deal, lack of transparency and exchange for shares is fairly cumbersome and the general form is:

$\Delta \bar{r}=-\alpha_{3} r_{n}+\alpha_{2} \Delta \beta f\left(r_{b}, r_{n}^{\prime}-r_{n}\right)+\Delta \gamma r_{c}$

and by (4) it must be non-negative. Note that the middle term in (6) represents two opposing effects: the increase in $\beta$ and the loss of the firm's equity if $\boldsymbol{r}_{n}^{\prime}-\boldsymbol{r}_{\boldsymbol{n}}<0$.

The above represent the definitions of changes in the expected risk adjusted rates of return for the control owner. This will now be generalized to establish the value of control as a sellable asset that another control seeker would be willing to pay for.

\subsection{Generalized model}

Consider the following framework. The value of the entire holdings of a control owner $\overline{\boldsymbol{V}}$, is given by,

$\bar{V}=\alpha_{1} V_{p}+\alpha_{2} \beta\left(V_{b}-V_{c}^{\prime}\right)+\alpha_{3} V_{n}+\gamma V_{c}$

where $\boldsymbol{\alpha}_{\mathbf{1}}$ is the fraction of the overall wealth invested in a closely-held private portfolio of investments whose value is $\boldsymbol{V}_{\boldsymbol{p}}, \boldsymbol{\alpha}_{2}$ is the fraction of the wealth invested in a $\boldsymbol{\beta}$ of the shares of a publicly traded firm, whose value is $\boldsymbol{V}_{\boldsymbol{b}}$. With some loss of generality, $\boldsymbol{V}_{\boldsymbol{b}}-\boldsymbol{V}_{\boldsymbol{c}}^{\prime}$, the value of the public firm $\boldsymbol{V}_{\boldsymbol{b}}$, net of private benefits of control $\boldsymbol{V}_{\boldsymbol{c}}^{\prime}$, can be viewed as the overall market value of the dividend claim of the publicly traded firm. $\boldsymbol{\alpha}_{3}, \boldsymbol{a}_{3}=\mathbf{1}-$ $\boldsymbol{a}_{1}-\boldsymbol{a}_{2}$, is the fraction of the wealth allocated for a new investment, whose value is $V_{n}$ that has just been undertaken. $\boldsymbol{V}_{\boldsymbol{c}}$ is the value of the overall benefits of control extracted by the control owners, who possesses a power index of $\gamma$, which represents the likelihood that they will be able to control the decisions of the public firm.

The new investment has been made for a price of $\boldsymbol{X}$. It is reasonable to assume that initially, $\boldsymbol{X}=\boldsymbol{V}_{\boldsymbol{n}}$, where $\boldsymbol{V}_{\boldsymbol{n}}$ is the expected value of the new investment. This can take the form of a one-shot investment or the cumulative value of investments made within a certain period of time. Most likely the price that has been paid reflects the expectations that the risk adjusted rate of return on this investment will not be inferior to the expected risk adjusted return on the private portfolio. Some uncertainty has been resolved and the control owners realize that the expected value of this investment is $\boldsymbol{V}_{\boldsymbol{n}}$, which may be different from $\boldsymbol{X}$. They face several options: they can retain the new investment as part of their privately held portfolio, they can sell the new investment to a third party, or they can attempt to transfer it to the public firm for the best price they can obtain, with a minimal risk that this transaction will ever be challenged in court. The control owners have a finite length of time, $\tau$, to make this decision.

In some countries it would be more realistic to add leverage; i.e., the control owners lever both their holdings and the purchase of new investments and thereby increases the potential gain and the level of risk. However, leverage is not essential for the purpose of the model, especially since the model will need to include the likelihood of personal bankruptcy of the control owners. In Israel, for instance, seven such major tycoons, over a period of five years, have gone bankrupt due to excessive personal leverage.

The control owners face a set of opportunities of new investments and believe that the value of a new investment follows a stochastic process,

$\frac{d V_{n}}{V_{n}}=\mu_{n} d t+\sigma_{n} d Z_{n}$ 
where $\boldsymbol{\mu}_{\boldsymbol{n}}$ the positive is instantaneous drift term, $\boldsymbol{\sigma}_{\boldsymbol{n}}$ is the instantaneous standard deviation and $\boldsymbol{d} \boldsymbol{Z}_{\boldsymbol{n}}$ represents the Weiner process. Initially the control owners believe that new investments evolve identically to their own private portfolio, i.e.

$\frac{d V_{n}}{V_{n}}=\frac{d V_{p}}{V_{p}}$

Simultaneously, the value of the public firm follows a similar process,

$\frac{d V_{b}}{V_{b}}=\mu_{b} d t+\sigma_{b} d Z_{b}$

with the parameters $\mu_{b} \sigma_{b}$ and a correlation between the processes of $\boldsymbol{\rho}_{\boldsymbol{n} \boldsymbol{b}}$. All the parameters are assumed to be constant.

Let $\boldsymbol{P}\left\{\boldsymbol{V}_{\boldsymbol{n}}, \boldsymbol{V}_{\boldsymbol{b}}, \boldsymbol{Y}, \boldsymbol{\tau}\right)$ be the value of a put option held by the control owners to exchange the new investment with the public firm for an expected cash price of $Y$. This option reflects the ability of the control owners to truncate the distribution of returns on new investments that they undertake. Initially, $\boldsymbol{V}_{\boldsymbol{n}}=\boldsymbol{X}$ where the price $\boldsymbol{X}$ reflects the belief that the expected risk adjusted rate of return is similar to that of the closely held portfolio, but after some uncertainty has been resolved $\boldsymbol{V}_{\boldsymbol{n}}$ may change. The control owners have a limited time of $\tau$ to pursue this option since longer would be a negative signal to the minority shareholders and reduce the level of trust in the motives of the control owners.

It is argued that $\boldsymbol{V}_{\boldsymbol{c}}=\boldsymbol{P}\left\{\boldsymbol{V}_{\boldsymbol{p}}, \boldsymbol{V}_{\boldsymbol{b}} ; \boldsymbol{V}_{\boldsymbol{n}}, \boldsymbol{Y}, \boldsymbol{\tau}\right)$ represents the benefits of control that stem from the ability of the control owners to optimize their holdings. A portion of $\boldsymbol{V}_{\boldsymbol{c}}$ may be labeled as 'private' benefits of control, $\boldsymbol{V}^{\prime}{ }_{\boldsymbol{c}}$, if it constitutes an appropriation of the resources of the public firm.

$\boldsymbol{P}\left\{\boldsymbol{V}_{\boldsymbol{p}}, \boldsymbol{V}_{\boldsymbol{b}} ; \boldsymbol{V}_{\boldsymbol{n}}, \boldsymbol{Y}, \boldsymbol{\tau}\right)$ Is an implicit contingent put option on the maximum of two risky assets. Margrave (1978) established a simple framework for the exchange of risky assets. Following Stulz (1982) established a rigorous framework for valuation of this type of option and demonstrated the parity relationships for various cases. The case applicable to this setting is a special case.

Consider a portfolio as (7) whose value behaves according to,

$d V=\beta \frac{\partial V}{\partial V_{b}} d V_{b}+\frac{\partial V}{\partial V_{p}} d V_{p}-\frac{\partial V}{\partial \tau} d_{t}+.5\left\{\frac{\partial^{2} \mathrm{~V}}{\partial V_{\mathrm{b}}^{2}} V_{b}^{2} \beta^{2} \sigma_{b}^{2}+\frac{\partial^{2} \mathrm{~V}}{\partial V_{\mathrm{p}}^{2}} V_{p}^{2} \sigma_{p}^{2}+2 \beta \frac{\partial^{2} \mathrm{~V}}{\partial V_{\mathrm{p}} \mathrm{V}_{\mathrm{b}}} V_{p} V_{b} \rho_{b p} \sigma_{b} \sigma_{p}\right\} d t$

Utilizing the notion of self financing portfolio, the differential equation becomes,

$$
\begin{aligned}
& -\frac{\partial V}{\partial \tau}=r\left\{V-\beta \frac{\partial V}{\partial V_{b}} d V_{b}-\frac{\partial V}{\partial V_{p}} d V_{p}\right\}-.5\left\{\frac{\partial^{2} V}{\partial V_{b}^{2}} V_{b}^{2} \beta^{2} \sigma_{b}^{2}+\frac{\partial^{2} V}{\partial V_{p}^{2}} V_{p}^{2} \sigma_{p}^{2}+\right. \\
& \left.2 \beta \frac{\partial^{2} V}{\partial V_{p} V_{b}} V_{p} V_{b} \rho_{b p} \sigma_{b} \sigma_{p}\right\} d t
\end{aligned}
$$

Two less crucial issues are disregarded. The first is the cross-homogeneity of the self- financing weights in the state variable. This is correctible under some assumptions and is discussed below. Second, only the European derivatives are considered whereas under a free boundary condition during $\boldsymbol{\tau}$ it can be solved numerically.

\subsection{Case one - a fair deal and full transparency}

The case of a fair deal and full transparency and $\boldsymbol{R}_{\boldsymbol{n}}=\boldsymbol{R}_{\boldsymbol{p}}=\boldsymbol{R}_{\boldsymbol{b}}$ is of no interest since the value of the option is null and no transfer of assets will take place. The case of a fair deal and full transparency when $\boldsymbol{R}_{\boldsymbol{n}}>\boldsymbol{R}_{\boldsymbol{b}}$ is driven by the definition of a fair deal. Under the notion of a fair deal $(3,5)$ and $(2)$, the negotiated transfer price, $Y$, is set so that the control owners are indifferent to either retaining the asset, or transferring it to the controlled public firm, while the net expected gains in lieu of the excess risk-adjusted expected return, if any, is allocated to the minority shareholders. In this case the control owners are not able to benefit by truncating the distribution of returns of new investments that they face and therefore the value of the option is nil.

Alternatively, a different definition of a fair game can be envisioned where the minority shareholders would not be worse off as a result of the transfer. This would be so in the event that the transferred asset has an expected risk adjusted rate of return greater than that of the firm, $\left(\boldsymbol{R}_{\boldsymbol{n}}>\boldsymbol{R}_{\boldsymbol{b}}\right)$, but the control owners justifiably demand some compensation for their positive contribution to the firm. Thus, they would transfer the asset if and only if $Y$ was high enough so that they could mitigate some or all of the losses, $X-Y$ (in the event that $\boldsymbol{R}_{\boldsymbol{p}}>\boldsymbol{R}_{\boldsymbol{n}}>$ 
$\boldsymbol{R}_{\boldsymbol{b}}$ ), provided that the minority shareholders would not be worse off. This restricted but valuable option will be analyzed later as a special case.

\subsection{Case 2 - lack of transparency, payment by cash}

The control owners considers a new investment $\boldsymbol{V}_{\boldsymbol{n}}$ whose price, $\boldsymbol{X}$, reflects the expected risk adjusted return on their existing portfolio, $\boldsymbol{r}_{\boldsymbol{p}},\left(\boldsymbol{V}_{\boldsymbol{n}}=\boldsymbol{\alpha}_{3} \overline{\boldsymbol{V}}=\boldsymbol{X}\right)$. The control owners estimate that after making the investment, in the event that they revise expectations; i.e., the expected return might be lower than previously expected, they can transfer the investment to the public firm for a price of $Y$ with a probability ${ }^{4}$ of $\gamma$, or keep the investment, or sell it elsewhere to a third party for $\boldsymbol{V}_{\boldsymbol{n}} . \quad Y$ can be a fixed amount, state dependent, or bounded by the risk adjusted return of the public firm (see next case). $Y$ can be conditionally committed at the time that the investment was undertaken ${ }^{5}$.

The control owners have an option which allows them to avoid some of the negative outcomes of the distribution of return on new investments. If we assume that the expected risk adjusted return of the private portfolio and the firm equity are the same, it would collapse to the less interesting case in which their entire gain would stem from the ability to transfer the asset for an excessive price. In this trivial case, the boundary condition on their payoff at the end of the period, $\boldsymbol{\tau}$, is a standard put option,

$M A X_{\tau}\left[(1-\beta)\left(Y-V_{n}\right), 0\right]$

However, this is a trivial case for several reasons. First, the expected risk adjusted return on the private portfolio is assumed to be higher than that of the firm. Second, the effect of the new investment on the existing private portfolio in the event that the option is NOT exercised varies with the size factor $\boldsymbol{\alpha}_{1}$ and $\boldsymbol{\alpha}_{3}$ as well as the effect, possibly positive, on the firm's value ( $\boldsymbol{\alpha}_{2}$ and $\boldsymbol{\alpha}_{3}$ ). Last, but less crucially, the expected rates of return on the existing private portfolio and firm's assets may change independently, irrespective of the decision to exercise the option.

Adding these assumptions and forcing the end of period boundary condition for the value of the option to be in a solvable form,

$$
\operatorname{MAX} X_{\tau}\left[Y-\operatorname{MIN}\left\{V_{b *}, V_{p^{*}}, 0\right\}\right]
$$

where the specific forms of $\boldsymbol{V}_{\boldsymbol{b} *}, \boldsymbol{V}_{\boldsymbol{p} *}$ given $\boldsymbol{\beta}$ will be specified in each case. In cases in which the benefits of control are 'private' the solution is iterative, since given (2) the higher the portion of value of the option attributed to 'private' benefits, the lower the remaining equity held by the minority shareholders. The critical point of optimal exercise $\boldsymbol{V}_{\boldsymbol{n}}^{*}$, is the maximal $\boldsymbol{V}_{\boldsymbol{n}}$ at which $\boldsymbol{V}$, the overall value of the holdings of the control owners, satisfies $V$ (retained) $=V$ (exercised). At this point the control owners are indifferent to either retaining the new investment and the option to transfer the investment into the public firm is not exercised. The critical exercise point depends on the parameters of the model. Interestingly, the critical point of optimal exercise may exceed $Y$, thereby enabling the control owners to transfer the new investment while avoiding the risk of being challenged in court.

The general form solution, $V_{c}$ is,

$V_{c}+\left\{(1-\beta) Y-V_{n}^{*}\right\} e^{-r_{\tau} \tau}$

$=\{(1-\beta) Y\} e^{-r f} \tau-C\left\{\operatorname{Min}\left(V_{b^{*}}, V_{p^{*}}\right), 0, \tau\right\}+C\left\{\operatorname{Min}\left(V_{b^{*}}, V_{p^{*}}\right), V_{n}^{*}, \tau\right\}$

i.e., the value of the put option on the minimum of two risky assets plus a constant equals a constant less the value of a call option on the minimum of two risk assets with a zero exercise price plus a call option on the minimum of two risk assets with an exercise price of $\boldsymbol{V}_{\boldsymbol{n}}^{*}$ (the artificial separation of the constants is meant to conform to the solution given by Stulz (1982)).

(The proof is given in appendix 1).

The middle term in the RHS of (15), $\boldsymbol{C}\left\{\boldsymbol{M} \boldsymbol{i n}\left(\boldsymbol{V}_{\boldsymbol{b}^{*}}, \boldsymbol{V}_{\boldsymbol{p} *}\right), \mathbf{0}, \boldsymbol{\tau}\right\}$ is the case presented by Margrave (1978) of an option to exchange two risky assets (the solution is given in the next section). The overall solution to (15) is,

\footnotetext{
${ }^{4}$ Since $\gamma Y$ is an expected value there is some risk associated with $Y$. See Kriezberg Teall (2009) for analysis of this risk.

5 The supporting valuation for the purpose of a potential transfer can be done around the purchase date whereas the process may take time and its outcome; i.e., transfer or no transfer, may still be uncertain.
} 


$$
\begin{aligned}
& C\left\{\operatorname{Min}\left(V_{b *}, V_{p^{*}}\right), V_{n}^{*}, \tau\right\}= \\
& V_{b *} N_{2}\left\{\frac{\ln \left(\frac{V_{b *}}{V_{n}^{*}}\right)+r^{f} \tau+.5 \sigma_{b}^{2} \tau}{\sigma_{b} \sqrt{\tau}}, \frac{\ln \left(\frac{V_{p *}}{V_{b *}}\right)-.5 \tau\left(\sigma_{b}^{2}+\sigma_{p}^{2}-2 \rho_{b p} \sigma_{b} \sigma_{p}\right)}{\sqrt{\tau\left(\sigma_{b}^{2}+\sigma_{p}^{2}-2 \rho_{b p} \sigma_{b} \sigma_{p}\right)}}, \rho_{b p} \sigma_{p}-\sigma_{b}\right\}+ \\
& V_{p *} N_{2}\left\{\frac{\ln \left(\frac{V_{p_{*}}}{V_{n}^{*}}\right)+r^{f} \tau+.5 \sigma_{p}^{2} \tau}{\sigma_{p} \sqrt{\tau}}, \frac{\ln \left(\frac{V_{b *}}{V_{p *}}\right)-.5 \tau\left(\sigma_{b}^{2}+\sigma_{p}^{2}-2 \rho_{b p} \sigma_{b} \sigma_{p}\right)}{\sqrt{\tau\left(\sigma_{b}^{2}+\sigma_{p}^{2}-2 \rho_{b p} \sigma_{b} \sigma_{p}\right)}}, \rho_{b p} \sigma_{b}-\sigma_{p}\right\}- \\
& V_{n}^{*} e^{r f t} N_{2}\left\{\frac{\ln \left(\frac{V_{p *}}{V_{n}^{*}}\right)+r f_{\tau+.5 \sigma_{p}^{2} \tau}}{\sigma_{p} \sqrt{\tau}}, \frac{\ln \left(\frac{V_{p *}}{V_{n}^{*}}\right)+r f \tau+.5 \sigma_{p}^{2} \tau}{\sigma_{p} \sqrt{\tau}}, \rho_{b p}\right\}
\end{aligned}
$$

where $\boldsymbol{N}_{\mathbf{2}}\{$.$\} is the bivariate cumulative standard normal distribution with upper limits of \boldsymbol{h}, \boldsymbol{k}$ and correlation of $\boldsymbol{\rho}^{6}$. Fortunately, the solution can be simplified under some assumptions which are not less robust than the assumptions needed to compute the above.

\subsection{Simplification}

Let us make several reasonable assumptions. First, assume that as long as the option is available to the control owners, the difference between the risk adjusted return of their initial private portfolio and the initial firm's assets $\boldsymbol{r}_{\boldsymbol{p}}-\boldsymbol{r}_{\boldsymbol{b}}$, is constant. Second, assume constant price/earnings ratios. Setting the two risky variables as:

$V_{p *}=V_{n}$

$V_{b *=} \boldsymbol{Y}+\boldsymbol{\beta}\left(\boldsymbol{V}_{\boldsymbol{n}}-\boldsymbol{Y}+\Delta \boldsymbol{V}_{\boldsymbol{b} / r_{n}}\right)$

where $\Delta \boldsymbol{V}_{\boldsymbol{b}} / \boldsymbol{r}_{\boldsymbol{n}}$ is the change in the value of the firm. It is computable given the assumptions above. The above solution collapses to the simple case of an option to exchange two risky assets. Following Margrave (1978), the solution can be easily computed, where the critical exercise point at the end of the period occurs when $\boldsymbol{V}($ retained $)=\boldsymbol{V}($ transfer $)$,

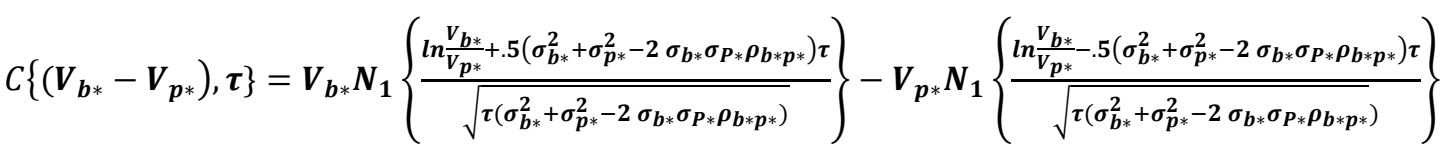

with homoscedastic standard deviations $\boldsymbol{\sigma}_{\boldsymbol{b} *}, \boldsymbol{\sigma}_{P *}$ a correlation coefficient $\boldsymbol{\rho}_{\boldsymbol{b} * \boldsymbol{p} *}$ and no dividend payout during $\boldsymbol{N}_{\mathbf{1}}\{$.$) is the univariate-normal cumulative standard density function.$

In order to isolate the value of 'private' benefits, we need to identify the states in which the public firm would sustain a loss as a result of the transfer. Thus the boundary condition for the value of the options with "no loss" for the firm is,

$$
\left.\operatorname{MIN}_{\tau}\left\{V_{b^{*}}, V_{p^{*}}, 0\right\}\right]-M I N_{\tau / V_{b *}>V_{p *}}\left[Y-V_{b *}, 0\right]
$$

(19) is a portfolio of two options: a put option held and a written "trigger" put option whose value depends on the likelihood that the control owners will exercise their option. The value of the written put option, $\boldsymbol{P}\left(\boldsymbol{V}_{\boldsymbol{b} *}, \boldsymbol{Y}, \boldsymbol{\tau}\right)$, is the fraction attributed to private benefits of control.

Thus, in this case the value of the option held by the control owners is,

$$
V_{c}=C\left\{\operatorname{Min}\left(V_{b *}-V_{p^{*}}\right), 0, \tau\right\}-P\left(V_{b *}, Y, \tau\right)
$$

Finally, the control owners have an option whose value is given above, but the expected value of the benefits of control should consider the likelihood of a transfer, or the power index $\boldsymbol{\gamma}$. In the unrestricted case with no constraint as in (20) on the effect on the minor shareholders,

$\gamma V_{c}=\gamma C\left\{\operatorname{Min}\left(V_{b *}-V_{p *}\right), 0, \tau\right\}$

The modification in (21) is important for the next section where the case of an exchange for equity is derived.

\footnotetext{
${ }^{6}$ See Abramowitz and Stegun (1964) 26.3.11.
} 


\subsection{Case 3 - payment by equity}

In this case the transfer of a new investment is likely to be in exchange for additional shares, $\Delta \boldsymbol{\beta}$, that are newly issued by the public firm. The control owners have superior information about the new investment that was recently undertaken privately. $\Delta \boldsymbol{\beta}$ seems to be equivalent to $Y$ in the previous section, given the likelihood of $\boldsymbol{\gamma}$, that the transfer will be approved, if the control owners had wanted to go ahead with the transfer. However, there is a difference in this case since $\boldsymbol{\gamma}$ is a function of $\boldsymbol{\beta}+\Delta \boldsymbol{\beta}$, the fraction of the shares the control owners possess in the public company. The additional expected value of control, due to an increase in $\gamma$, is not a "free lunch" since someone must "pay" for it and it may be incorporated into the negotiations with the control owners as regards the size of $\Delta \boldsymbol{\beta}$ received in exchange for the new investment. Thus the solution is this case is an iterative one. We must incorporate the fact that as in (2), the additional expected value of control may reduce the remaining 'dividend claim value' and therefore this portion of the added value of control must be considered as 'private' benefits of control.

Similar to the previous case, this is not necessarily a 'zero sum game'. The case of a zero sum game is the one in which equal expected risk adjusted returns on the private portfolio and the firm's equity are assumed. As stated above, it is assumed here that the private portfolio has a superior risk adjusted expected return and even if the control owners decide to 'dump' inferior new investments on the public firm, given their expectations, the minority shareholders may still benefit.

Interestingly, though this case seems to be more complicated, the mathematical formulation is simplified since it collapses to the Margrave (1978) case of an option to exchange two risk assets. The end of period boundary condition is,

$\operatorname{MAX}_{\boldsymbol{\tau}}\left\{\boldsymbol{V}_{b^{*}}-\boldsymbol{V}_{p^{*}}, 0\right\}$

where $\boldsymbol{V}_{\boldsymbol{b} *}$ is the event of a transfer and $\boldsymbol{V}_{\boldsymbol{p} *}$ is the event that the control owners retain the new investment,

$$
\begin{aligned}
& V_{p^{*}}=V_{n} \\
& V_{b *=}(\boldsymbol{\beta}+\Delta \beta)\left(V_{n}+V_{B}+\Delta V_{b / r_{n}}-\beta V_{b}+\Delta \gamma\left(V_{n}+V_{b}\right)+V_{c}\right.
\end{aligned}
$$

Thus, the solution has the same form as (18) but $\boldsymbol{V}_{\boldsymbol{b} *}, \boldsymbol{V}_{\boldsymbol{p} *}$ are specified differently, incorporating interactively the change in $\boldsymbol{V}_{\boldsymbol{c}}$ as well as $\boldsymbol{\sigma}_{\boldsymbol{b} *}, \boldsymbol{\sigma}_{P *}$ and $\boldsymbol{\rho}_{\boldsymbol{b} * \boldsymbol{p} *}$.

\subsection{Simulation}

The simulation procedure captures the effect of several parameters on the value of the benefits of control in lieu of an option possessed by the control owners to transfer new, less desirable investments from their own portfolio to a controlled public firm. The value of the benefits of control is measured as the added value relative to the size of the new investments; i.e., $\Delta \boldsymbol{V}_{\boldsymbol{c}} / \boldsymbol{V}_{\boldsymbol{n}}$. The impact of the following parameters was assessed:

a) The level of risk and degree of co-movements of the private portfolio, new investments and the public firm.

b) The degree of superiority of the private portfolio of the control owners. This parameter lends itself to the issue of separating 'private' benefits of control from the overall benefits of control.

c) Level of transparency measured by the difference, $\boldsymbol{Y}-\boldsymbol{V}_{\boldsymbol{n}}$. This can also be viewed as a measure of how tolerant a country's legal system is to such transfers.

d) (18) cannot be used to simulate the size effect of the new investments relative to the size of the firm or the private portfolio, $\boldsymbol{a}_{\mathbf{1}}$ and $\boldsymbol{a}_{3}$. For this purpose (16) needs to be simulated, which was not done here.

e) For simplicity and for practical purposes, the likelihood of exercise by the control owners was computed by $N_{1(.)}$ in (18) while the accurate measure has to be computed by (16). The difference, however, is not significant.

Step one analyzes the case in which the control owners are compensated by cash, if they decide to transfer a new investment. The case is characterized as unrestricted; i.e., by a lack of transparency and the minority shareholders of the public firm may not necessarily benefit from the transfer. $Y$ is set based on the valuation of the new investments that were made based on the information that was available around the time of the initial purchase by the control owners, but they have a period of $\boldsymbol{\tau}$ to decide whether to finalize the transfer or not. Table 1 presents the results for this case: 
Table 1: Payment by cash, lack of transparency, unrestricted case

\begin{tabular}{c|c|c|c|c|c|c|c|c|c|c|c|c|c|}
\hline \\
\hline
\end{tabular}

Column 1 - initial price for a new investment committed by the control owner as a fraction of the firm value, column 2 - the same as (1) if the new investment is transferred to the firm, column 3 - cash paid by the public firm, column 4 - fraction of shares of the public firm possessed by the control owner, column 5 - the risk adjusted expected return on the private portfolio, column 6 - the risk adjusted expected return of the equity of the public firm, column 7 and 8 - the critical values as per equation (17) as a fraction of the firm value, column 9-11 - standard deviations and correlation coefficients, column 12 duration of the period in which the control owners have to decide, column 13 - the added value of control as a fraction of the firm value, column 14 - the added value of control as a fraction of the value of the new transferred investment.

The second case is the restricted case; i.e., we restrict the value so that the minority shareholders are not worse off, but all the gains are appropriated to the control owners. This is reported in Table 2 as the fraction of private benefits of control out of the entire benefits.

Table 2: Payment by cash, lack of transparency, private benefits

\begin{tabular}{|c|c|c|c|c|c|c|c|c|c|c|c|}
\hline Column1 & Column2 \\
\hline
\end{tabular}

Column 1 - initial price for a new investment committed by the control owner as a fraction of the firm value, column 2 - the same as (1) if the new investment is transferred to the firm, column 3 - cash paid by the public firm, column 4 - fraction of shares of the public firm possessed by the control owner, column 5 - the risk adjusted expected return on the private portfolio, column 6 - the risk adjusted expected return of the equity of the public firm, column 7 and 8 - the critical values as per equation (17) as a fraction of the firm value, column 9-11 - standard deviations and correlation coefficients, column 12 duration of the period in which the control owners have to decide, column 13 - the added value of control as a fraction of the firm value, column 14 - the value of the private benefits of control, column 14 - the fraction of private benefits from the total value of benefits of control.

The third case analyzes payments for the transfer by equity. In this case, the added value of control is also affected by the change in the holdings of the control owners in the shares of the public firm. Thus, the solution is iterative. This case was restricted to be a 'fair game' in the sense that the gains in lieu of the transfer, if any, are allocated to the shareholders of the firm ${ }^{7}$. In practice, however, the control owners would go ahead with the transfer if and only if the quantity of shares given as payment was higher than what is reported in Table 3 .

\footnotetext{
${ }^{7}$ In this case the value of the option may not be considered as a benefit of control and is constant for a given set of $\boldsymbol{\sigma}_{\boldsymbol{b} *}, \boldsymbol{\sigma}_{P *}$ and $\boldsymbol{\rho}_{\boldsymbol{b} * p_{*}}$.
} 
Table 3: Payment by equity, iterative, fair game

\begin{tabular}{|c|c|c|c|c|c|c|c|c|c|c|c|c|}
\hline Column1 $\nabla$ & Column2 & Column3 & Column4 & Column5 & Column6 & Column7 & Column8 & Column9 & Column10 & $\nabla$ & Column11 & Column12 \\
\hline$X / V_{b}$ & $\beta$ & $\Delta \beta$ & $\Delta \gamma$ & $r_{p}$ & $r_{b}=r_{f}$ & $\sigma_{P_{k}}$ & $\sigma_{b *}$ & $\rho_{b \leqslant p k}$ & $\tau$ & & $\Delta V_{c} / V_{b}$ & $\Delta V_{c} / V_{n}$ \\
\hline $10 \%$ & $50 \%$ & $3.7819 \%$ & $0.9455 \%$ & $4 \%$ & $2 \%$ & 0.35 & 0.25 & 0.5 & & 1 & $0.620 \%$ & $16.603 \%$ \\
\hline $10 \%$ & $50 \%$ & $3.6077 \%$ & $0.9019 \%$ & $8 \%$ & $2 \%$ & 0.35 & 0.25 & 0.5 & & 1 & $0.620 \%$ & $16.124 \%$ \\
\hline $10 \%$ & $50 \%$ & $3.5210 \%$ & $0.8802 \%$ & $10 \%$ & $2 \%$ & 0.35 & 0.25 & 0.5 & & 1 & $0.620 \%$ & $15.886 \%$ \\
\hline $10 \%$ & $40 \%$ & $4.0369 \%$ & $1.4533 \%$ & $10 \%$ & $2 \%$ & 0.35 & 0.25 & 0.5 & & 1 & $0.620 \%$ & $22.190 \%$ \\
\hline $10 \%$ & $60 \%$ & $2.8412 \%$ & $0.4546 \%$ & $10 \%$ & $2 \%$ & 0.35 & 0.25 & 0.5 & & 1 & $0.620 \%$ & $11.204 \%$ \\
\hline $10 \%$ & $50 \%$ & $3.6733 \%$ & $0.9183 \%$ & $4 \%$ & $2 \%$ & 0.55 & 0.25 & 0.5 & & 1 & $0.942 \%$ & $19.526 \%$ \\
\hline $10 \%$ & $50 \%$ & $3.4995 \%$ & $0.8749 \%$ & $8 \%$ & $2 \%$ & 0.55 & 0.25 & 0.5 & & 1 & $0.942 \%$ & $19.048 \%$ \\
\hline $10 \%$ & $50 \%$ & $3.4131 \%$ & $0.8533 \%$ & $10 \%$ & $2 \%$ & 0.55 & 0.25 & 0.5 & & 1 & $0.942 \%$ & $18.811 \%$ \\
\hline $10 \%$ & $40 \%$ & $3.9102 \%$ & $1.4077 \%$ & $10 \%$ & $2 \%$ & 0.55 & 0.25 & 0.5 & & 1 & $0.942 \%$ & $24.909 \%$ \\
\hline $10 \%$ & $60 \%$ & $2.7567 \%$ & $0.4411 \%$ & $10 \%$ & $2 \%$ & 0.55 & 0.25 & 0.5 & & 1 & $0.942 \%$ & $14.276 \%$ \\
\hline $10 \%$ & $50 \%$ & $3.7302 \%$ & $0.9325 \%$ & $4 \%$ & $2 \%$ & 0.45 & 0.25 & 0.5 & & 1 & $0.774 \%$ & $17.998 \%$ \\
\hline $10 \%$ & $50 \%$ & $3.5562 \%$ & $0.8890 \%$ & $8 \%$ & $2 \%$ & 0.45 & 0.25 & 0.5 & & 1 & $0.774 \%$ & $17.520 \%$ \\
\hline $10 \%$ & $50 \%$ & $3.4696 \%$ & $0.8674 \%$ & $10 \%$ & $2 \%$ & 0.45 & 0.25 & 0.5 & & 1 & $0.774 \%$ & $17.282 \%$ \\
\hline $10 \%$ & $40 \%$ & $3.9765 \%$ & $1.4315 \%$ & $10 \%$ & $2 \%$ & 0.45 & 0.25 & 0.5 & & 1 & $0.774 \%$ & $23.487 \%$ \\
\hline $10 \%$ & $60 \%$ & $2.8009 \%$ & $0.4481 \%$ & $10 \%$ & $2 \%$ & 0.45 & 0.25 & 0.5 & & 1 & $0.774 \%$ & $12.670 \%$ \\
\hline
\end{tabular}

Column 1 - initial price for a new investment committed by the control owner as a fraction of the firm value, column 2 fraction of shares of the public firm possessed by the control owner, column 3 - the fraction of the firm's equity given to the control owner as a payment, column 4 - the change in the power index, column 5 - the risk adjusted expected return on the private portfolio, column 6 - the risk adjusted expected return of the equity of the public firm, column 7-9 standard deviations and correlation coefficients, column 10 - duration of the period in which the control owners have to decide, column 11 - the added value of control as a fraction of the firm value, column 12 - the added value of control as a fraction of the value of the new transferred investment.

\subsection{Implications and conclusion}

The analysis above has several implications. First, not all the benefits of control are 'private' in the sense that they constitute an appropriation of resources from publicly held firms. The minority shareholders may benefit from the control owners' actions by having exposure to a wider variety of investment opportunities to which otherwise they would not have access.

Second, it is clear that control owners who want to maximize the value of the benefits of control will undertake riskier new investments so that the value of the option increases. In fact, as increasingly more investments are transferred to the firm, the level of risk of the firm's asset increases. Thus, the control owners will take ever more risky new investments.

Finally, it would be useful to compare the simulation results with empirical findings that are based on the sales of controlling blocks among control seekers. These empirical findings are likely to demonstrate higher values of control. However, due to the practical difficulties of obtaining empirical data, the results of the model here could be used as an efficient tool, since they require knowing fewer parameters.

\section{References}

Abramovitz, M., and I. A. Stegun, Handbook of mathematical Functions, 1964, National Bureau of Standards.

Admati A., P. Pfleiderer and J. Fechner, "Large Shareholder Activism, Risk Sharing, and Financial Market Equilibrium", Journal of Political Economy, Vol. 102, No. 6 (Dec., 1994), pp. 1097-1130 http://dx.doi.org/10.1086/261965.

Barclay, M. and C. Holderness, "Private Benefits of Control of Public Corporations," Journal of Financial Economics, 1989, 371-395. http://dx.doi.org/10.1016/0304-405X (89)90088-3.

Bebchuk, L., "Efficient and Inefficient Sales of Corporate Control," Quarterly Journal of Economics, 1994, 109, 957-994. http://dx.doi.org/10.2307/2118353.

Bebchuk, L. and L. Zingales, "Corporate Ownership Structures: Private versus Social Optimality", 1996, NBRE Working Paper 5584.

Bergstrom, C and K. Rydqvist, "Ownership of Equity in Dual Class Firms," Journal of Banking and Finance, 1990, 14, pp. 237-253 http://dx.doi.org/10.1016/0378-4266 (90)90049-8.

Coffee, J, "Do Norms Matter? A Cross-country Examination of Private Benefits of Control", 2001, Columbia University Law School \#283. 
DeAngelo, H. and L. DeAngelo, "Managerial Ownership of Voting Rights," Journal of Financial Economics, 1985, 14, 36-39. http://dx.doi.org/10.1016/0304-405X(85)90043-1.

Demsetz, H. and K. Lehn, "The Structure of Corporate Ownership: Causes and Consequences", Journal of Political Economy, Vol. 93, No. 6 (Dec., 1985), pp. 1155-1177 http://dx.doi.org/10.1086/261354.

Dyck, A. and L. Zingales, "Private Benefits of Control: An International Comparison" Journal of Finance, 2004, 59, 2, pp. 537-600. http://dx.doi.org/10.1111/j.1540-6261.2004.00642.x.

Fluck, Z. "The dynamics of the management-shareholder conflict," Review of Financial Studies, 1999, 12, 379404 http://dx.doi.org/10.1093/rfs/12.2.379.

Grossman, S., and 0. Hart, "Takeover bids, the free rider problem, and the theory of the corporation," The Bell Journal of Economics, Vol. 11, No. 1 (Spring, 1980), pp. 42-64. http://dx.doi.org/10.2307/3003400.

Grossman, S., and 0. Hart, "One share one vote and the market for corporate control," Journal of Financial Economics, 1988, 20(1-2), 175-202. http://dx.doi.org/10.1016/0304-405X(88)90044-X.

Harris, M. and A. Raviv, "Corporate Governance: Voting Rights and Majority Rules," Journal of Financial Economics, 1988, 20, 203-235. http://dx.doi.org/10.1016/0304-405X(88)90045-1.

Holmström, B. and J. Tirole, "Market liquidity and performance monitoring", Journal of Political Economy, Vol. 101, No. 4 (Aug., 1993), pp. 678-709 http://dx.doi.org/10.1086/261893.

Jensen, M. and W. Meckling, "Theory of the Firm, Managerial Behavior, Agency Costs and Ownership Structure," Journal of Financial Economics, 1976, vol. 3, pp. 305-360. http://dx.doi.org/10.1016/0304405X(76)90026-X.

Kraizberg E. and J. Teall, "The Distribution and Valuation of Corporate Control ", Open Business Journal, 2009, 2, pp 28-42 http://dx.doi.org/10.2174/1874915100902010028.

La Porta, R., F. Lopez-de-Salines, and A. Shleifer, "Investor Protection and Corporate Governance," Journal of Financial Economics, 2000, 59 (1-2), 3-27. http://dx.doi.org/10.1016/S0304-405X(00)00065-9.

La Porta, R., F. Lopez-de-Salines, and A. Shleifer, "Corporate Ownership around the World." Journal of Finance, 1999 54(2): 471-517. http://dx.doi.org/10.1111/0022-1082.00115.

La Porta, R., F. Lopez-de-Salines, A. Shleifer and R. W. Vishny. "Investor Protection and Corporate Governance," 2008, London and New York: Taylor and Francis, Routledge.

Lease, R. C., J. McConnell, and J. Mikkelson, and H. Wayne "The Market Value of Control in Publicly- Traded Corporations." Journal of Financial Economics, 1983, Vol. $11 \quad(1-4), \quad$ p $439-71$. http://dx.doi.org/10.1016/0304-405X(83)90019-3.

Lease, R. C., J. McConnell, and J. Mikkelson, and H. Wayne, "The Market Value of Differential Voting Rights in Closely Held Corporations". Journal of Business, 1984, Vol. $57 \quad$ (4). $443-67$. http://dx.doi.org/10.1086/296274.

Levy, H., "Economic Evaluation of Voting Power of Common Stock", Journal of Finance, 38, 1983: 79-93. http://dx.doi.org/10.1111/j.1540-6261.1983.tb03627.x.

Margrabe, W., "The Value of an Option to Exchange on Asset to Another", Journal of Finance, (1978) V32-1, pp.177-187.

Milnor, J.W. and Shapley, L.S. "Values of Large Games II: Oceanic Games", Mathematics of Operations Research, 3, 1978: 290-307. http://dx.doi.org/10.1287/moor.3.4.290.

Nenova,T., "Essays on corporate control" Ph.D. Dissertation, 2001, Harvard, Dept. of Economics.

Owen, G. "Multilinear Extensions of Games", Management Science, 18, 1972: 64-79. http://dx.doi.org/10.1287/mnsc.18.5.64.

Roe, M. J, "Political and Legal Restraints on Ownership and Control of Public Companies". Journal of Financial Economics, 27.1 (Sep 1990): 7-41 http://dx.doi.org/10.1016/0304-405X(90)90019-V

Shapley, L.S. and Shubik, M. "A Method for Evaluating the Distribution of Power in a Committee System" American Political Science Review, 48, 1954: 787-792. http://dx.doi.org/10.2307/1951053.

Shleifer, A. and R. Vishny, "A survey of corporate governance," Journal of Finance, 1997, 52, 737-783. http://dx.doi.org/10.1111/j.1540-6261.1997.tb04820.x.

Stulz, R. and R.Williamson, "Culture, Openness, and Finance," NBER working paper 8222 (2001).

Stulz, R., "Option on the minimum or maximum of two risky assets; Analysis and Applications", Journal of Financial Economics 10 (1982) 161-185. http://dx.doi.org/10.1016/0304-405X(82)90011-3.

Teall, J. L. "A Binomial Model for the Valuation of Corporate Voting Rights," Journal of Business Finance and Accounting, June 1996, pp 603-616 http://dx.doi.org/10.1111/j.1468-5957.1996.tb01028.x.

Zingales, L., "What determines the value of corporate votes?," Quarterly Journal of Economics, 1995, 110,10471073. http://dx.doi.org/10.2307/2946648.

Zingales, L., "In Search of New Foundations," Journal of Finance, 2000, 55: 1623- 1653 http://dx.doi.org/10.1111/0022-1082.00262. 


\section{Appendix 1}

Proof that (15) is the solution for the value of the put option on the minimum of two risky assets.

\begin{tabular}{l|c|c}
\hline State & $\begin{array}{c}\text { Payoff at the end of the period } \\
\text { - left-hand side of (15) }\end{array}$ & $\begin{array}{c}\text { Payoff at the end of the period } \\
\text { - right-hand side }\end{array}$ \\
\hline $\operatorname{Min}\left(V_{b^{*}}, V_{p^{*}}\right) \geq V_{n}^{*}$ & $\left\{(1-\beta) Y-V_{n}^{*}\right\}$ & $\left\{(1-\beta) Y-V_{n}^{*}\right\}$ \\
\hline $\operatorname{Min}\left(V_{b^{*}}, V_{p^{*}}\right)=V_{b_{*}}<V_{n}^{*}$ & $\left\{(1-\beta) Y-V_{n}^{*}\right\}-V_{b^{*}}$ & $\left\{(1-\beta) Y-V_{n}^{*}\right\}-V_{b^{*}}$ \\
\hline $\operatorname{Min}\left(V_{b^{*}}, V_{p^{*}}\right)=V_{p^{*}}<V_{n}^{*}$ & $\left\{(1-\beta) Y-V_{n}^{*}\right\}-V_{p^{*}}$ & $\left\{(1-\beta) Y-V_{n}^{*}\right\}-V_{p^{*}}$ \\
\hline
\end{tabular}

Since the payoffs are identical in each state (15) may serve as a boundary condition. 